\title{
Age of patient at the extraction of the third molar
}

\author{
Kautto, A.
}

2018-07

Kautto , A , Vehkalahti , M M \& Ventä , I 2018 , ' Age of patient at the extraction of the third molar ' , International Journal of Oral and Maxillofacial Surgery , vol. 47 , no. 7 , pp. 947-951 . https://doi.org/10.1016/j.ijom.2018.03.020

http://hdl.handle.net/10138/310056

https://doi.org/10.1016/j.ijom.2018.03.020

cc_by_nc_nd

acceptedVersion

Downloaded from Helda, University of Helsinki institutional repository.

This is an electronic reprint of the original article.

This reprint may differ from the original in pagination and typographic detail.

Please cite the original version. 


\section{Age of patient at the extraction of the third molar}

Arja Kautto, Miira M. Vehkalahti, Irja Ventä

Department of Oral and M axillofacial Diseases, University of Helsinki, Helsinki, Finland

Address for correspondence: Irja Ventä, Department of Oral and Maxillofacial Diseases, Faculty of M edicine, P.O. Box 41, Fl-00014 University of Helsinki, Helsinki, Finland. Phone: +358 50 4151309, Fax: +358 9 19127265, Email: irja.venta@helsinki.fi

Sources of support: None.

Key words: third molar; extraction; operation; age; gender; diagnosis

Running head: Age at extraction of third molar 


\section{ABSTRACT}

The purpose of this study was to assess the age of patients at the time of extraction of third molars. Our data included all routine and surgical extractions of third molars ( $\mathrm{N}=8199$ teeth) performed by general and specialist dentists of the public oral health services of the city of Helsinki over the 2013-2014 period. M easurements included patient's age, gender, the identified third molar, the type of anaesthesia, the method of extraction, and the diagnosis at extraction. Patients' ages ranged from 10 to 99 years. We found significant differences between younger and older age groups: third molar extractions occurred more often for women than for men below the age of 30 years $(P \varangle 0.001)$ and vice versa for patients older than 30. Extractions were more prevalent for the upper jaw ( $P \varangle 0.001)$, and surgical extractions were more common than routine extractions $(P \varangle 0.001)$ below the age of 40 , but the corresponding prevalences reversed after the age of 40 . Diagnoses at extraction differed between younger and older patients. We conclude that the treatment pattern of third molars at public health services varies greatly over a lifetime, and that a greater variety exists than had been reported previously from oral and maxillofacial units. 


\section{INTRODUCTION}

The third molar is often referred to as the most commonly extracted tooth or it is associated with the most frequent surgical procedure. The most likely reason is because most studies of third molars are carried out by oral and maxillofacial surgeons and include patient samples from an oral and maxillofacial unit. Although these studies are very useful, they do not reveal the complete picture and the great variety in the treatment of third molars that exists in a population over a lifetime. Data on third molar studies are rarely gathered from primary care units with wide age ranges of patients that cover both routine and surgical extractions, and provided by both general and specialist dentists.

Little is known about how third molar extractions are distributed over the human life span. Epidemiological studies on the presence of third molars indirectly report the prevalence of extractions of third molars. According to these studies two thirds of all third molars are removed by the age of 30 to 40 years ${ }^{1-4}$. In addition, the mean age of patients at the time of extraction of third molars is usually reported from selected patient samples treated at oral and maxillofacial surgical units alone. The mean age may also reflect national trends ${ }^{5}$.

Indications for the extraction of third molars reported mainly in studies on young adults treated at surgical units are not the same for patients belonging to one of the other age groups in the human live span. The initial indications in young adults, such as prophylactic or orthodontic reasons, impaction, and pericoronitis, change to caries and periodontal diseases later in life $e^{6-10}$. In addition, studies on data obtained from oral and maxillofacial surgery units are usually limited to surgical extractions. Surgical extraction, however, may not be the predominant method of extraction of third molars over a lifetime.

The aim of this present study was to assess the age of patients at the time of extraction of third molars. We analyzed all third molar extractions performed in a public health care unit 
over a two-year period, and this unit includes general and specialist dentists that treat patients of all ages. Furthermore, this studied unit, the Social Services and Health Care of the city of Helsinki, is the largest unit of its kind in Finland, which provides public oral health care services.

\section{MATERIAL AND METHODS}

Approximately 190000 patients visit the public oral health care services of the city of Helsinki annually. Our register-based data cover all extractions of third molars that occurred from January 2013 through December 2014 inclusive. The search listed all third molars with any code for tooth extraction (Table 1). We excluded those teeth with the codes EBA40 and EBA45 (apicoectomies), and EBA15 for extraction of several teeth during the same appointment ( $n=237$ teeth). In total, 8199 teeth were enrolled in the analysis.

We recorded to the data identification of the tooth and jaw, the diagnosis, the type of anaesthesia, the method of extraction, the patient's age and gender at the time of extraction. The method of extraction was dichotomized as routine extraction (EBA00, EBA05, and EBA30) or surgical extraction (EBA10, EBA12, EBA20, and EBA99). We recorded the diagnosis of extraction according to the $10^{\text {th }}$ edition of International Classification of Diseases (ICD-10; Table 2).

The Department of Social Services and Health Care of the city of Helsinki granted permission to use these register-based data for research purposes (HEL 2014-012907). No additional institutional ethics committee approval was necessary because the study had no patient interventions in its protocol. 
We categorized the age of the patients into the following age groups: 10-19 years, 20-29 years, 30-39 years, $40-49$ years, 50-59 years, $60-69$ years, and 70 years and older. The chisquared test was used for assessing differences in frequencies between these age groups, genders, jaws, and methods of extraction. The level of significance was set at P-values $\varangle$.01. IBM SPSS Statistics version 24 (IBM Corp. Armonk, NY, USA) was used for the data processing.

\section{RESULTS}

During the 2-year period, 8199 third molars were extracted, $50.3 \%$ of the teeth were in men and $49.7 \%$ in women. Patient's mean age was 36.4 years (SD 15.0) and the median age was 32 years (range 10-99). Extractions were carried out with local anaesthetic in 93\% of the teeth under sedation in $5 \%$, and under general anaesthesia in $2 \%$.

Extractions of third molars started abruptly in the late teens and the peak age for extraction was 23, 24 and 25 years equally (Figure 1). Almost two-thirds of the extractions were performed between ages 20 to 39 years (Table 3). Women predominated for third molar extractions up to the age of 29 , whereas men predominated from 30 years of age $\left(\chi^{2}=84.770\right.$; $d f=6 ; P \varangle 0.001)$

Slightly under half (49\%) of the extracted third molars were in the maxilla and $51 \%$ in mandible. Extractions of upper third molars predominated up to the age of 39 years, and thereafter lower third molars from the age of 40 years on $\left(\chi^{2}=109.504 ; d f=6 ; P \varangle 0.001\right.$; Table 3). Routine extractions were the majority (72\%), the rest (28\%) were surgical extractions (Table 3 ). Surgical extractions were more likely to occur below the age of 40 years and routine extractions predominated after that $\left(\chi^{2}=178.221 ; d f=6 ; P<0.001\right)$. Difficulty of the extractions was distributed as follows: $52 \%$ were extractions with forceps (EBA00 code), $15 \%$ difficult 
extractions (EBA05; e.g. with separation of the tooth without raising a flap), $24 \%$ surgical extractions (EBA10; e.g. raising a flap and/or osteotomia and/or separation of the tooth), $4 \%$ difficult surgical extractions (EBA12; deep and difficult impactions), and 5\% were extractions of a root with forceps (EBA30).

M ost of the diagnoses (92\%) were attributed to the ICD10-class under the heading of Diseases of Oral Cavity, Salivary Glands and Jaws. The rest of diagnoses included among others fracture of the tooth (S02.5), dental examination (Z01.2), and convalescence following surgery (Z54.0). The most common diagnoses at extraction were gingivitis and periodontal diseases (23\%; including e.g. pericoronitis), diseases of pulp and periapical tissues (20\%), dental caries (17\%), and embedded and impacted teeth (13\%; Figure 2). Smaller frequencies, not shown in the Figure 2, were obtained for disorders of tooth development and eruption (K00; 7\%), dentofacial anomalies (K07; 5\%), other diseases of connective tissues and teeth (K08; 4\%), and other miscellaneous diagnoses (11\%). Diagnoses at extraction differed between younger and older patients.

\section{DISCUSSION}

The key result of the study demonstrated the changes in the extraction pattern of third molars in patients from 10 to 99 years of age. The most prominent findings were that third molar extractions in women began at an earlier age than in men, and that routine extractions were far more common than surgical extractions. The ages of 30 to 40 years proved to be a transition period over which the prevalence of surgical extractions changed to routine extractions and the prevalence of maxillary extractions changed to mandibular extractions. 
Oral health care services in Finland are available in both the public and private sectors. Since December 2002, the public oral health care services have been open to the whole population. The majority of the children younger than 18 years and almost half of the adult population use public services ${ }^{13}$. Oral surgery accounts for $5 \%$ of all treatment measures provided by public services ${ }^{14}$. The city of Helsinki has a population of 0.6 million and it has the largest unit in Finland that provides public oral health care services. The staff of this unit consists of about 200 dentists and includes specialists among whom 10 are oral and maxillofacial surgeons. Detailed information of the treatments at each visit is recorded in a computerized database using official codes that are uniform to all service providers. For all these reasons, our study material is representative for public oral health care services and thus meets the objectives of this study.

The mean age at extraction of third molars in our study at 36.4 years was rather high. However, mean age does not accurately represent average age at extraction because the distribution of ages at extractions was skewed and was highly predominant in the young age groups. The median age of 32 years ( $50 \%$ of extractions were done up to this age) in our study was lower than the mean age and gives a somewhat better indication of the pattern of extractions. The peak ages of 23,24 , and 25 years in this study were lower than the mean and median ages. Our peak extraction ages from 23 to 25 years was about the same as reported for mean age in earlier studies that had been carried out in oral and maxillofacial surgical units. A US-based study ${ }^{15}$ reported the mean age of 25 years but in another study ${ }^{8}$ that used insurancebased data, the age was as young as 17 or 18 years. A study from the UK reported that the mean age increased from 29 to 36 years between the years 1994 and $2012^{5}$. A Swedish study reported a mean age of 28 years for mandibular third molar extractions ${ }^{7}$. A Japanese investigation found that most third molars were extracted between 15 to 34 years of age ${ }^{16}$. 
Our results show that equal numbers of third molars were extracted in men and women whereas earlier studies report a slight predominance among female patients at oral and maxillofacial surgical units ${ }^{7,15}$. Our study, however, reveal a statistical significant difference between genders within the age groups: third molar extractions in women begin at an earlier age than in men. When only the youngest cohorts of our investigation are observed, a similar predominance in females as those reported in earlier studies from surgical units emerges. Findings of female predominance related to age are also found in the epidemiological study conducted by Magraw et al. ${ }^{4}$, in which men were more likely than women to have more third molars in all age groups up to the age of 70 years and thus, we can indirectly estimate that extractions were more likely in women than in men. However, there were major differences in the origin or background of the subjects between our study and the US study. One-third of the US subjects were Caucasians and two thirds were African Americans or other ethnic groups ${ }^{4}$. However, the ethnicity of a patient is not registered in the patient records in Finland. The percentage of persons with foreign background in Finland was 5.9\% in 2014, and is therefore a small proportion of the population. However, Helsinki where the study was carried out is the capital of Finland, and the prevalence of people of non-Finnish background during our study in 2013 and 2014 was $13-14 \% 17$.

Our study showed that equal numbers of third molars from both jaws were extracted. However, before the age of 40 years the maxillary third molars were extracted more often than were the mandibular third molars, whereas from 40 years onwards mandibular extractions predominated. In a US study $46 \%$ of third molar extractions at oral and maxillofacial surgical unit were maxillary third molars ${ }^{15}$. This slight difference between the findings may imply that upper third molars are not referred to specialist so often. M oreover, the usual practice in Finland is that after a maxillary third molar was extracted then the 
mandibular one on the same side of the jaw was also extracted one or two years later. This practice is to omit the occlusal forces and alleviate the extraction of the latter one.

Our findings for the method of extraction were different from those reported by earlier studies carried out at oral and maxillofacial units. We reported only $28 \%$ of third molars that were surgically extracted. In the US study the method of extraction was the opposite, i.e. $24 \%$ of removals were nonsurgical ${ }^{15}$. This difference between ours and the US study can be explained: nearly all extractions (93\%) carried out by the public health services were done under local anaesthesia whereas general anaesthesia was used in the US study in $67 \%$ of cases. Eklund and Pittman ${ }^{8}$ describe, in their study on insurance-based records, that the prevalence of surgical extractions of bony impacted third molars decreased with age, moving from $100 \%$ in patients younger than 20 to less than $10 \%$ after the age of 50 years. We reported similar prevalence for subjects older than 50 years. The profile of cases is thus different at oral and maxillofacial unit and at public oral health services.

The leading diagnoses in the youngest age groups were categorized into either code $\mathrm{KO1}$ or K05, i.e. impactions and pericoronitis, whereas among the subjects in older age groups other diagnoses were more common, i.e. caries, pulpal and periapical diseases along with gingivitis and periodontal diseases. Similar changes with age were reported in earlier studies although based mostly on data obtained regarding oral and maxillofacial surgical units or including mandibular third molars alone $e^{6-10}$. These results describe the usual successive development of dental diseases with age and a similar trend has also been found for diagnoses at extraction of teeth other than third molars $16,18,19$.

A limitation of our study is in the protocol of recording the diagnoses. When several treatments are done during a single appointment, only one diagnosis is registered. For example, if a filling is done to another tooth and an upper third molar is also extracted during 
the same appointment, the main diagnosis of that appointment is registered according to the most time-consuming treatment. However, when extracting third molars the entire appointment is usually reserved for that. When only one diagnosis is used, it may be that a third molar was diagnosed at extraction with caries, but was also partially erupted and thus impacted. More than one third molar may also be extracted during the same appointment. In the present study, the basic search to get the file used treatment code and tooth number and thus, the discrepancy in diagnoses of extractions may be considered insignificant.

We conclude that our study demonstrated the extraction pattern of third molars over a lifetime from 10 to 99 years of age at public oral health care services. This report differs from earlier studies on third molar extractions in that our material included but was not limited to an oral and maxillofacial surgical unit. Therefore, in the treatment of third molars a greater variation was than has been reported previously under more restricted studies. 


\section{Acknowledgements}

We thank DDS Tuomo Maisala from the Department of Social Services and Health Care of the city of Helsinki for gathering the data of this study.

Funding: None.

Competing interests: None.

Ethical approval: The Department of Social Services and Health Care of the city of Helsinki granted permission to use this register-based data for research purposes (HEL 2014-012907).

Patient consent: Not required.

Confirmation: All authors have viewed and agreed to the contents of the submission. 


\section{REFERENCES}

1. Hugoson A, Kugelberg CF. The prevalence of third molars in a Swedish population. An epidemiological study. Community Dent Health 1988: 5: 121-138.

2. Ventä I, Ylipaavalniemi P, Turtola L. Clinical outcome of third molars in adults followed during 18 years. J Oral M axillofac Surg 2004: 62: 182-185.

3. Suominen-Taipale L, Nordblad A, Vehkalahti M, Aromaa A (eds). Oral health in the Finnish adult population. Health 2000 Survey. Publications of the National Public Health Institute B25/2008, Helsinki Finland 2008.

http://www.julkari.fi/bitstream/handle/10024/103030/2008b25.pdf? sequence=1. [Accessibility verified January 25,2018$]$.

4. Magraw CBL, M oss KL, Fisher EL, Offenbacher S, White RP Jr. Prevalence of visible third molars in the United States population: How many individuals have third molars? J Oral Maxillofac Surg 2016: 74: 13-17.

5. Petrosyan V, Ameerally P. Changes in Demographics of Patients Undergoing Third M olar Surgery in a Hospital Setting between 1994 and 2012 and the Influence of the National Institute for Health and Care Excellence Guidelines. J Oral Maxillofac Surg 2014: 72: 254-258.

6. Lysell L, Rohlin M. A study of indications used for removal of the mandibular third molar. Int J Oral Maxillofac Surg 1988: 17: 161-164.

7. Knutsson K, Brehmer B, Lysell L, Rohlin M. Pathoses associated to third molars subjected to removal. Oral Surg Oral Med Oral Pathol Oral Radiol Endod 1996: 82: 1017.

8. Eklund SA, Pittman JL. Third-molar removal patterns in an insured population. J Am Dent Assoc (JADA) 2001: 132: 469-475. 
9. Fuster-Torres M A, Gargallo-Albiol J, Berini-Aytes L, Gay-Escoda C. Evaluation of the indication for surgical extraction of third molars according to the oral surgeon and the primary care dentist. Experience in the Master of Oral Surgery and Implantology at Barcelona University Dental School. M ed Oral Patol Oral Cir Bucal 2008: 13(8): E499504.

10. Renton T, Al-Haboubi M, Pau A, Shepherd J, Gallagher JE. What has been the United Kingdom's experience with retention of third molars? J Oral M axillofac Surg 2012: 70(Suppl 1): S48-S57.

11. National Institute for Health and Welfare. Classification of procedures of oral health 2016. Chapter E. Procedures of teeth, lips, jaws, mouth, and throat: Extraction of teeth. National Institute for Health and Welfare. Helsinki 2015:62-63. https://www.julkari.fi/bitstream/handle/10024/129612/URN_ISBN_978-952-302-6001.pdf?sequence $=1$. [Accessibility verified January 25, 2018].

12. World Health Organization. International Statistical Classification of Diseases and Related Health Problems 10th Revision (ICD-10)-WHO Version for 2016. Chapter XI. Diseases of the digestive system. Diseases of oral cavity, salivary glands and jaws. World Health Organization, 2016.

http://apps.who.int/classifications/icd10/browse/2016/en. [Accessibility verified January 25, 2018].

13. Widström E, Komu M , M ikkola H. Longitudinal register study of attendance frequencies in public and private dental services in Finland. Community Dent Health 2013: 30: 143-148.

14. Widström E, Linden J, Tiira H, Seppälä TT, Ekqvist M. Treatment provided in the public dental service in Finland in 2009. Community Dent Health 2015: 32: 60-64. 
15. Susarla SM, Dodson TB. Predicting third molar surgery operative time: A validated model. J Oral M axillofac Surg 2013: 71: 5-13.

16. Aida J, Morita M, Akhter R, Aoyama H, M asui M, Ando Y. Relationships between patient characteristics and reasons for tooth extraction in Japan. Community Dent Health 2009: 26: 104-109.

17. Official Statistics of Finland. Persons with foreign background. Statistics Finland, Helsinki, 2016. http://pxnet2.stat.fi/explorer/M aahanmuuttajat_2016. [Accessibility verified January 25,2018$]$.

18. Trovik TA, Klock KS, Haugejorden 0 . Trends in reasons for tooth extractions in Norway from 1968-1998. Acta Odontol Scand 2000: 58: 89-96.

19. Chrysanthakopoulos NA. Reasons for extraction of permanent teeth in Greece: a fiveyear follow-up study. Int Dent J 2011: 61: 19-24. 


\section{Tables}

Table 1. The classification codes for procedures used in the search: based on the National Institute for Health and Welfare in Finland ${ }^{11}$.

\begin{tabular}{ll}
\hline Code & Operation \\
\hline EBA00 & Extraction \\
EBA05 & Difficult extraction \\
EBA10 & Surgical extraction \\
EBA12 & Difficult surgical extraction \\
EBA15 & Extraction of several teeth ${ }^{\text {a }}$ \\
EBA20 & Hemisection \\
EBA30 & Extraction of root \\
EBA40 & Apicoectomy, single-rooted \\
EBA45 & Apicoectomy, multi-rooted \\
EBA99 & Other surgical extraction \\
\hline aExtraction of at least four teeth from a jaw during infection control.
\end{tabular}


Table 2. M ain classes of the entity of Oral Cavity, Salivary Glands and Jaws according to the International Classification of Diseases ${ }^{12}$ (10th Revision) and some examples found in the study.

\begin{tabular}{|c|c|c|}
\hline Code & Diagnosis & Including \\
\hline K00 & Disorders of tooth development and eruption & Disturbances in tooth eruption \\
\hline K01 & Embedded and impacted teeth & Impacted tooth \\
\hline K02 & Dental caries & Caries of dentine \\
\hline K03 & Other diseases of hard tissues of teeth & Dental calculus \\
\hline K04 & Diseases of pulp and periapical tissues & Pulpitis, periapical abscess \\
\hline K05 & Gingivitis and periodontal diseases & Pericoronitis \\
\hline K06 & $\begin{array}{l}\text { Other disorders of gingiva and edentulous } \\
\text { alveolar ridge }\end{array}$ & Irritative hyperplasia \\
\hline K07 & Dentofacial anomalies (including malocclusion) & $\begin{array}{l}\text { Temporomandibular joint } \\
\text { disorders }\end{array}$ \\
\hline K08 & Other diseases of connective tissues and teeth & Retained dental root \\
\hline K09 & Cysts of oral region & Follicular cyst \\
\hline K10 & Other diseases of jaws & Alveolitis of jaws \\
\hline K11 & Diseases of salivary glands & - \\
\hline $\mathrm{K} 12$ & Stomatitis and related lesions & Submandibular abscess \\
\hline K13 & Other diseases of lip and oral mucosa & Cheek and lip biting \\
\hline K14 & Diseases of tongue & Black hairy tongue \\
\hline
\end{tabular}


Table 3. Distribution (\%) of the extracted third molars ( $\mathrm{N}=8199$ teeth) according to gender, jaw, and method of extraction, by age group.

\begin{tabular}{|c|c|c|c|c|c|c|c|}
\hline & Gender & & Jaw & & Method & xtraction & \\
\hline Age group & Men & Women & Maxilla & Mandible & Routine & Surgical & Total \\
\hline (years) & $\%$ & $\%$ & $\%$ & $\%$ & $\%$ & $\%$ & n (\%) \\
\hline $10-19$ & 43 & 57 & 7 & 6 & 5 & 11 & $549(7)$ \\
\hline $20-29$ & 45 & 55 & 38 & 31 & 34 & 36 & $2824(34)$ \\
\hline $30-39$ & 54 & 46 & 27 & 25 & 25 & 28 & $2108(26)$ \\
\hline $40-49$ & 53 & 47 & 13 & 15 & 15 & 12 & 1164 (14) \\
\hline $50-59$ & 57 & 43 & 9 & 11 & 11 & 7 & 801 (10) \\
\hline $60-69$ & 57 & 43 & 4 & 7 & 6 & 4 & $451(5)$ \\
\hline $70-99$ & 55 & 45 & 2 & 5 & 4 & 2 & $302(4)$ \\
\hline Percentage & 50 & 50 & 49 & 51 & 72 & 28 & $8199(100)$ \\
\hline P-value ${ }^{a}$ & $\varangle 0.001$ & & $\varangle 0.001$ & & $\varangle 0.001$ & & \\
\hline
\end{tabular}




\section{Captions to illustrations}

Figure 1. Histogram of third molar extractions ( $N=8199$ teeth), by patients' ages.

Figure 2. Distribution (\%) of the four most common diagnoses ( $n=6035$ teeth) at extraction, by age group. These four diagnoses comprise $73 \%$ of all diagnoses of the material. Acute and chronic pericoronitis belong to the category of $\mathrm{K} 05$.

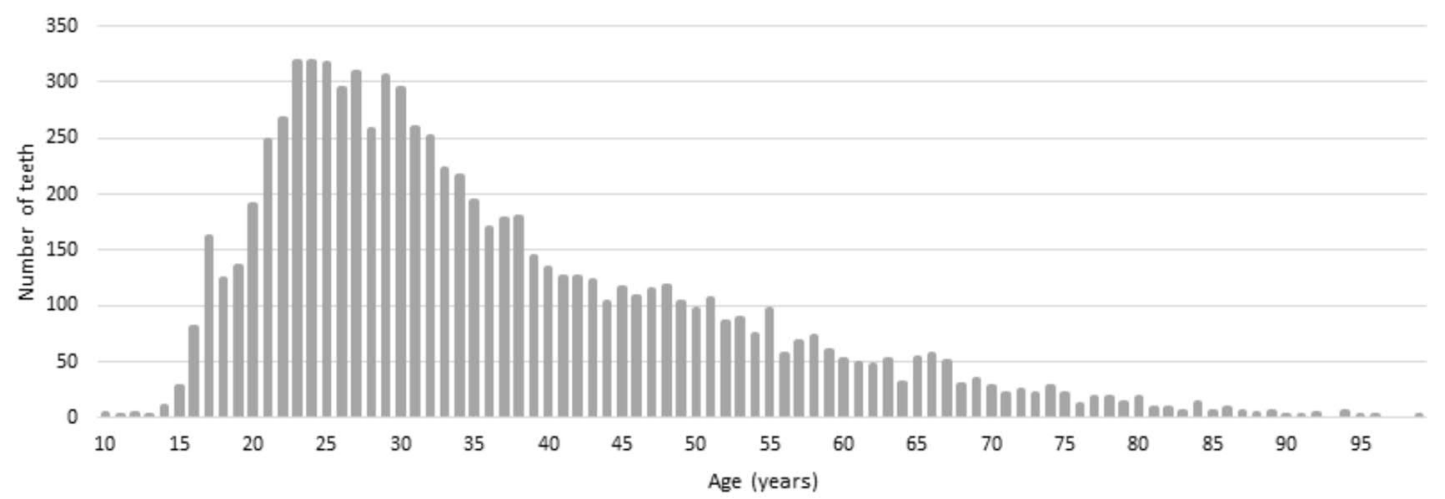

Figure 1. 


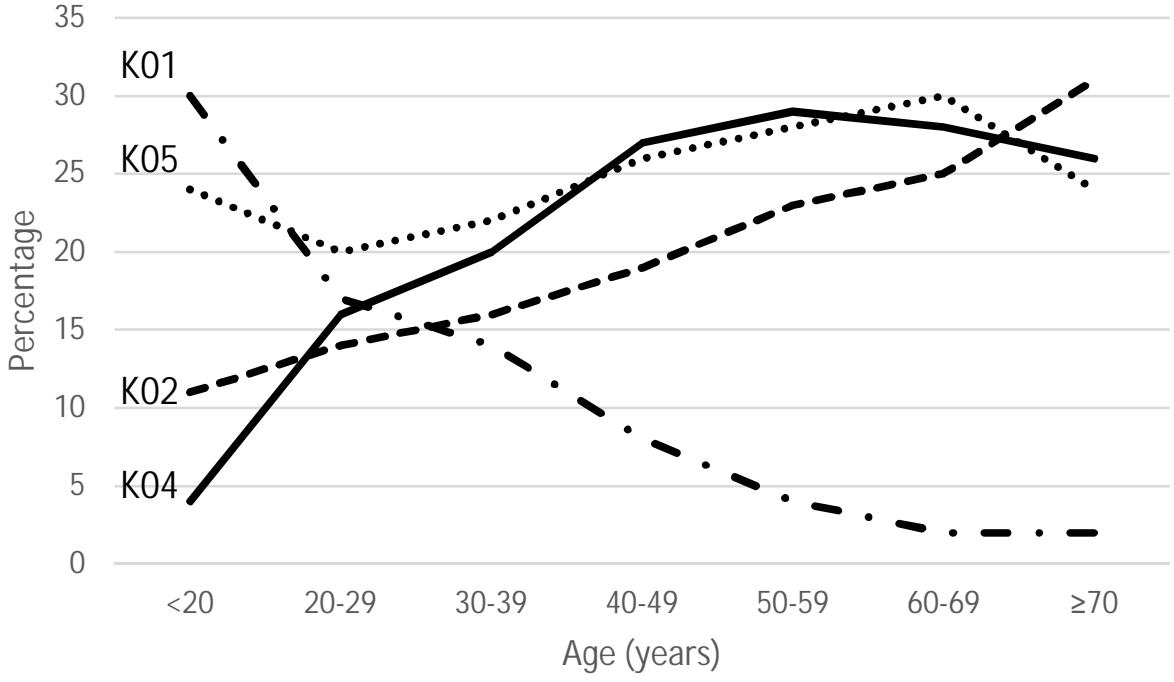

- - K01 Embedded and impacted teeth

- - K02 Dental caries

K04 Diseases of pulp and periapical tissues

...... K05 Gingivitis and periodontal diseases

Figure 2. 